\title{
Study on Management System of Commodity Market of Virtual Network Economy of Modern Internet Finance
}

\author{
Wu Xiaohui \\ Shanghai Jiaotong University, Shanghai, China
}

\begin{abstract}
The rapid development of computer technology has brought great innovation to the operation of commodity economy. The emerging technology industries give an unprecedented release to the society productivity, including Internet finance, cloud computing, big data, intelligent manufacturing, automated factories, etc. The exchanged means and mediums of commodity economy develop from the traditional precious metals and banknote to electronic currency trading products produced by the mobile clients. The manufacturing scale and marketing channels of social commodity have achieved an unprecedented prosperity and extension. At this stage where the complex and changeable new industries rapidly replace the old ones, fully-automatic intelligent production management gradually replaces old-fashioned extensive labor-intensive manufacturing model, so as to lead to industry reforms of interactive exchange platforms of commodity manufacture transferring to the controllable, hi-speed, and personalized customization service controlled by remote terminal management.
\end{abstract}

Keywords: Internet finance, electronic currency, intelligent manufacturing, virtual products

\section{Introduction}

The medium currencies of commodity economy exchange change rapidly with the continuous development of human society. The currencies used in human's history change from the earliest money cowrie to metal currency, then banknote, and now the emerging electronic currency. The development of commodity economy is constantly changing the forms of currency. Before stepping into the electronic currency age, commodity exchanges between people started from the traditional practicality manufacturing activities to networked virtual data production. Virtual data products have a vast value development space rooted in the modern economy. Virtual finance has a close association and interaction with the real economy, which plays an important guiding role in the modern industrial economy market.

To balance the inflation caused by the excessive issue and economic contraction caused by the deficiency of issue, what need to do is to balance the interests' distribution relations of different social classes according to the needs of the market production input and products purchasing power of consumer groups' demand. The produced quantity of precious metals basically decided the circulation areas of commodity exchange and service groups in the period when precious metal currencies are the main means of circulation of trading for social materials. The production of precious metals is limited and quantitative, and their value in the

Wu Xiaohui, master, School of Foreign Language, Shanghai Jiaotong University, Shanghai, China.

Correspondence concerning this article should be addressed to Wu Xiaohui, 9th Flood, Building-2 of Jia Bang Guo Jin Center, Shilong South Road No. 1, Nanhai District, Foshan 528251, Guangdong, China. 
commodity exchange is closely associated with their production costs. People regard precious metals as an asset value and long-term storage of wealth protection in the market transaction.

When banknote becomes the main medium of exchange, the efficiency of social and economic commodity exchange was greatly improved. Banknotes were widely issued to the social group through the government behavior, whose manufacturing cost is low, and can realize the authority and the rationality of the circulation by applying proprietary technology. Compared with metal currency, the social circulation of banknotes is more likely to be controlled and adjusted, which obviously brings convenience for people's living and promotes the economy. The use of banknote, of course, also has its deficiencies. The paper itself doesn't have the value given by the productive labor, and is unable to conserve and maintain value for a long time, and the issue financial institutions have difficulty in timely grasping and fully adjusting the scale and circulation way of banknotes.

With the rapid development and upgrading of computer industry, the emerging e-money products begin to step into people's life. Compared with metal and paper currency, electronic money has an unprecedented circulation advantage. When electronic money becomes a commodity circulation means, people's economic activities can be all-round displayed in the transaction data in a clearer way. The daily transaction data can be fine to individuals, and can quickly learn the overall economic operating situation.

Electronic currency's performance in the market allows ubiquitous and updating behaviors of production, sales, and purchase. Connect the operation of the entire commodity market with a network transaction basis point, and suppliers and demand sides begin seamless docking, like the ends of the scale, so as to rapidly progress in fine tuning. Starting from the analysis of the present e-commerce development trend, the interactive influences of the development of virtual network economy to the change of commodity market management are as follows.

\section{The Popularity of a Fast and Efficient Internet Self-help Virtual Currency Exchange System}

Since the mid 1990s, the Internet finance began to appear in China and constantly innovated with two rounds of rapid development. (1) From the mid 1990s to the early 21st century, China experienced the first-round rapid development of the Internet finance marked with network bank, network stock, and network insurance. (2) Since 2010s, China's Internet finance started the second wave of development, with a starting point of rapid development of modern science and technology, such as social networking, mobile payment, cloud computing, and search engine (Feng, 2013).

Internet finance self-help virtual currency exchange system is rooted in the purpose of realizing the automatic finance circulation. When merchandise is no longer confined to capacity obstacles caused by paper money in circulation, the Internet finance brings a kind of new collaborative management mechanism combining currency and commodity. Individuals produce virtual data products, and at the same time, they provide product services and production technology prototypes for exhaustive product users through Internet. The rates of visit and use of virtual data products can be produced massively as a reference to the virtual financial forms, and can be converted to individuals' purchasing power and disposable wealth, which makes the shared data assets become rapidly-expanding social proprietary material resources.

Its measurement standard is the data and information quantity of value assessment. Computer intelligent CNC automatic platforms control the issue of electronic currency. On the one hand, it can gradually achieve fully-automated data finance management mode, on the other hand, it can have a rapid expansion and 
promotion of special custom factories in goods area, which make the production behavior of commodity economy and consumption activities achieve the two-way connection and achieve the coordination effect.

\section{Build Widely-Accepted Recoil Structure Management of Electronic Currency}

Socialized issue of electronic currency serves for the commodity production scale, and the controllable electronic currency circulation can bring huge promotion to commodity production. Recently, the Internet finance models typical of the third-party payment, the network credit institutions, and the P2P lending platform increasingly arouse people's attention, and the third-party payment is increasing almost at the speed of doubling every year. The growth of loans scale of network credit institutions and their interest income are striking, with the constant emergence of P2P lending platforms (Guo, 2013; Huang, 2001).

Under the virtual currency system, virtual product producers can turn the results manufactured by their own production units into the form of virtual data and upload to Internet public service platform, so as to provide corresponding modular technical information data results for the targeted data collecting users. After data users gain the public network data results, virtual product producers can set electronic monetary rewards according to the directional data click, by which can bring fast incremental extension on sales channels to the virtual product suppliers, and effectively dig out the working enthusiasm and creativity potential of the virtual product producers.

Independent self-help electronic currency recoil structure can be integrated and served for each interest linked in the market economy activity. The main contents of electronic currency trading recoil mechanisms include:

(1) The third-party payment system is not only the convenient tool of monetary transfer and payment, but also the issue source of currency input and finance sales. The equivalent cohesion of electronic finance and production scale can protect healthy operation of commodity economy management channel.

(2) Union of the issuing principle of currency and the layout of the service object selection area can effectively promote economic finance and avoid market volatility. Internet finance is gradually changing people's attitude towards traditional consumption, and aims at building new business marketing channels and convenient market trading environment with scope of choosing and buying goods.

(3) The third-party payment is a network certification licensing evaluation way of public virtual products. The controllable scale materialization production of virtual products can effectively improve the speed of product development and supply and the efficiency of customization production.

\section{The Promotion of Virtual Network Economy to Manufacturing Production Lines of Remote-Controlled, Intelligent-Managed, and Mechanization Products}

The rapid progress of computer technology provides unprecedented business development opportunities for people's economic activities, and leads to the rapid development of manufacturing level and change of lifestyles. People's wealth management is gradually entering the period of virtualization and networking, and commodity production capacity is gradually becoming automatic and intelligent, and at the same time, the manufacture of the goods gradually steps from semi-automatic to fully automatic.

When the same big intelligent integrated factories become a set of manufacturing services as a home printer carrier terminal, individual users can be commodity producers and users at the same time, and when individual users create proprietary virtual data on the network transaction platform, they won the data financial rewards in the platform, while the proprietary virtual data can be directly tailored to the predicted network consumer products on the remote intelligent manufacturing line. 


\section{Internet Financial Model’s Convenience for Building Individual Buyers Regional Networked Product Customization Service Chain}

Internet financial model can produce huge social benefits. Now Internet financial model can achieve the same efficiency of resource allocation as direct and indirect financing. And it significantly reduces transaction costs while promoting economic growth. More importantly, in the Internet financial mode, division of labor and specialization of present finance industry will be replaced by the Internet and its related software technology; market participants are more popular, and the huge benefit caused by the Internet finance market exchange will be more beneficial for ordinary people (Xie, 2012; Sun, 2012; Zhang, 2007).

After the Internet platform breaks the regional market restrictions, the circulation range and speed of goods get a huge ascension. A product can cut down a large amount of tedious circulation sections from designer to users. Individual buyers' willingness is paid more attention by the general suppliers than ever before. Personalized customization gradually enters into people's daily consumption concepts. Intelligent manufacturing factories bring low demand for labor, and in the process of the intensive labor production enterprises transferring to high-end automatic program-controlled technology enterprise, a large number of labor workers with low output efficiency transfer to developers of high professional and technical production management. Knowledge technology shows its important position in the production process.

A new developed product can be a virtual data product of labors. And this product can be manufactured by intelligent programmes from time to time, and the production process of its products can be completed by numerical control lathe, 3D printing technology, and intelligent production line. This is a huge revolution brought by science and technology to the traditional labor mode. Comprehensive goods manufacturing factories can match the data according to the regional materials needs to enlarge the total production volume of virtual data, and at the same time, realize the involved float of regional comprehensive manufacturing capacity and promote regional diversified industries integration and resource circulation. Apply the product information data flow to gradually ease high-load and constantly increasing regional production and marketing of products, and appropriately release the infinitive cross-region labor distribution of the workers.

\section{Multi-predictedly Coordinate and Develop Network Market Trading Platform of Personal Virtual Data Products}

Building a reasonable service organization mechanism of virtual network commodity exchange includes many management departments. In the organization of virtual commodity exchange, it can be set: coordination association, finance bureau, material department, assessment team, management room, exchange bourse, foreign exchange bank, credit cooperatives agency, fleet team, warehouse, sales hall, pawn shop, scientific bureau, processing factory, the recycle bin, and other departments, so as to coordinate the function division of each department and market positioning.

The set of these management departments coordinate is close in the market, which can bring positive and effective guidance to each channel of commodity production and management, and stimulate the orderly operation of the market economy activities. This department setting mode is a system arrangement and organization setting based on the balanced distribution of wealth level, production, and marketing and supply chain, just like the self-regulation of organs of the living things to energy flow and the suction line cycle system in the body. 


\section{Regional Self-help Products Integrated Customized Manufacturing Business Model}

The nature of commercial activity is four-rate cycled activity, including commodity flow, cash flow, information flow, and logistics. E-commerce depends on the rapid flow of information on the basis of the Internet industry, and speeds up the logistics, commodity flow, and capital flow. In traditional e-commerce activities, funds flow only depends on one-way flow of e-commerce platform. Taking B2B electric company as an example, funds flow from a supplier to another supplier through electric business platform; for B2C and C2C, funds flow from consumers to the seller through electric business platform. However, electrical business finance completely changes one-way operation way of funds in the previous e-commerce activities, makes capital form a closed loop within the electricity business ecosystem, and realizes the capital circulation and accelerating turnover (Huang, 2013; Zhang, 2008).

When the commodity production steps into the controlled scale production, NC equipment of computer automatic production provides accelerating and simplified conditions for production lines. The production of goods between different factories form a correlation, which can be the transmission of product data parameters and the interaction of business cooperation channels and material circulation, so as to carry out conditional modularization management of commodity production.

Integrated production factories can effectively prevent the product backlog in the process of the same kind of commodity production, realize connection between market demand and the buyer's scope and provide substantial supply for each other. In order to do it, according to time inconsistency, the high-speed updating is needed. For smart customization production factory assembly line setting, it can take classified and systemic design to cohere different production lines, and implement integrated management of reversible free product assembly chains.

The integrated intelligent production factories can refer to the procurement requirements of large community supermarkets and adopt commodity supply and recycling schemes of customization production. Its function is to realize the repurchase and utilization of regional local materials and circulation of materials circulation, so as to achieve diversified and controllable market sales management mechanism and orderly sales of goods in the regions, and mitigate and reduce the excess material waste caused by the marketing and supply chain and the blindly labor resource consumption.

\section{References}

Feng, J. J. (2013). Research on competitive strategies of commercial banks under the background of the Internet finance. Journal of Modern Finance, 5(4), 14-16.

Guo, S. B. (2013). How banks meet the rising of the Internet. Journal of Outstanding Financial Management, 6(3), 10-11.

Xie, P. (2012). Face the challenges and opportunities of Internet finance model. The 21st century economic report.

Huang, H. L. (2013). Research on Internet finance cored with electronic business platform. Shanghai Finance, 4(8), 14-17.

Huang, Z. J. (2001). Network economics. Beijing: China Financial and Economic Publishing House.

Sun, J. (2012). Study on the influence of network economy on the modern enterprise and Chinese enterprise tactics. Journal of Public Administration \& Governance, 2(2), 1-8.

Zhang, J. L. (2007). Research of network economy. Science and Technology News, 2, 21-26.

Zhang, Y. C. (2008). Enterprise development opportunities and challenges under the condition of network economic. Journal of Luohe Vocational Technical College, 1, 35-36. 